\title{
ANÁLISE POR TRIANGULAÇÃO DE MÉTODOS: UM REFERENCIAL PARA PESQUISAS QUALITATIVAS
}

\section{ANALYSIS BY TRIANGULATION OF METHODS: A REFERENCE TO QUALITATIVE RESEARCH}

\author{
Nilsen Aparecida Vieira Marcondes ${ }^{1}$ \\ Elisa Maria Andrade Brisola²
}

Resumo: Este artigo tem como objetivo discutir informações já publicadas sobre um dos procedimentos analíticos voltados à interpretação de dados qualitativos, qual seja, a Análise por Triangulação de Métodos. Em se tratando da metodologia, esta pesquisa se apresenta quanto à forma de abordagem do assunto, como qualitativa, do ponto de vista de seus objetivos, como descritiva e com relação aos procedimentos técnicos, caracteriza-se como bibliográfica. Os resultados deste estudo teórico demonstram que este instrumental analítico contribui no desenvolvimento de pesquisas qualitativas voltadas à interpretação e atribuição de significados dos fenômenos investigados, favorecendo o processo de análise indutiva dos dados coletados. Como conclusão, considera-se que a Análise por Triangulação de Métodos reforça a importância do diálogo entre os dados empíricos, autores que tratam da temática estudada e análise de conjuntura, num contínuo movimento dialético.

Palavras-chave: referencial analítico; pesquisas qualitativas; Análise por Triangulação de Métodos.

\begin{abstract}
This article aims to discuss information already published about one of the analytical procedures aimed at interpreting qualitative data, called Analysis by Triangulation of Methods. In terms of methodology, this type of research may be described as qualitative from the point of view of its objectives, as descriptive in relation to the technical procedures, characterized as a study of literature. The results of this theoretical study show that this analytic tool helps in the development of qualitative research focused on the interpretation and attribution of meanings to the phenomena investigated, favoring the process of inductive analysis of the data collected. In conclusion, it is considered that the analysis by triangulation methods reinforces the importance of the dialogue between the empirical data, the authors dealing with the subject studied, and analyze situations in a continuous dialectical movement.
\end{abstract}

Keywords: analytical reference; qualitative research; Analysis by Triangulation of Methods.

\footnotetext{
1 Mestre em Desenvolvimento Humano: Formação, Políticas e Práticas Sociais - Universidade de Taubaté - Unitau e Assistente Social da Prefeitura Municipal de São José dos Campos - SP. E-mail: nilsenmarcondes@gmail.com.

2 Doutora em Serviço Social - Pontifícia Universidade Católica de São Paulo - PUC-SP e Docente da Unitau. E-mail: elisabrisola@uol.com.br.
} 


\section{INTRODUÇÃO}

Tendo como tema a Análise por Triangulação de Métodos, interessa, neste estudo teórico, tratar sobre um dos muitos Referenciais Analíticos destinados a contribuir no desenvolvimento das pesquisas, particularmente das pesquisas qualitativas.

Diante da indagação: "Como analisar os dados de uma pesquisa qualitativa por meio da Triangulação de Métodos?", buscou-se demonstrar, neste artigo, as etapas de tal procedimento. Portanto, esta indagação, considerada como o problema deste estudo, foi o que motivou todo o processo reflexivo ora apresentado.

Justifica-se a importância do debate em torno desta realidade na ambiência acadêmica porque se considera o assunto como intrínseco e vital a todo e qualquer procedimento reflexivo, crítico e de busca de respostas para questões a serem desvendadas.

O objetivo deste estudo pauta-se na discussão de informações já publicadas sobre um dos procedimentos analíticos voltados à interpretação de dados qualitativos, qual seja, a Análise por Triangulação de Métodos.

Defende-se como relevante o tema porque se reconhece que na ciência, a área da pesquisa, enquanto viabilizadora do processo de construção do conhecimento, é caracterizada pela busca da qualidade formal. Essa busca pela qualidade formal diz respeito aos meios e formas utilizadas na produção do trabalho. Portanto, a interpretação dos dados é tão importante quanto outras fases da pesquisa, como, por exemplo, o domínio de técnicas de coleta de dados e a manipulação de fonte de informações.

A pesquisa se configura como "[...] um conjunto de ações, propostas para encontrar a solução para um problema, que têm por base procedimentos racionais e sistemáticos” (MORESI, 2003, p. 8). Nesse sentido, a interpretação dos dados e a atribuição de significados são temas essenciais a serem discutidos e analisados na área da investigação científica. Assim sendo, entende-se que propiciar reflexões sobre Referenciais Analíticos se apresenta sempre como ordem do dia na área da pesquisa.

Gerar conhecimentos que possam subsidiar pesquisadores em geral nas suas tarefas analítico-interpretativas é atribuição que merece atenção. O desenvolvimento de reflexões em torno dos Referenciais Analíticos demanda ampla discussão; por isso, limita-se este estudo a tratar somente da Análise por Triangulação de Métodos que se caracteriza como um dos muitos Referenciais Analíticos existentes num processo de pesquisa.

$\mathrm{Na}$ elaboração do estudo, foram encontradas algumas obras de autores como Deslandes (2004), Gomes (2004), Gomes et al. (2010), Minayo (2010), e um livro denominado Avaliação por Triangulação de Métodos: Abordagem de Programas Sociais cuja obra é bastante esclarecedora. Organizado, em 2005, por Maria Cecília de Souza Minayo, Simone Gonçalves de Assis e Edinilsa Ramos de Souza, ele é consequência do esforço teórico-prático de pesquisadores da Escola Nacional de Saúde Pública, da Fundação Osvaldo Cruz no Rio de Janeiro.

Quanto à forma de abordagem do assunto, o estudo caracteriza-se como qualitativo. Defende- 
se que a busca pelo foco qualitativo dentro da pesquisa é de grande valia, pois se concorda com as análises de Minayo (2004, pp. 21-22), quando faz referência à pesquisa qualitativa, como aquela que: "[...] trabalha com o universo de significados, motivações, crenças, valores e atitudes, o que corresponde a um espaço mais profundo de relações, dos processos e dos fenômenos que não podem ser reduzidos à operacionalização".

Do ponto de vista dos objetivos, este estudo se caracteriza como descritivo. É considerado como descritivo porque o interesse centrou-se na observação, registro e análise das obras dos autores que tratam da Análise por Triangulação de Métodos. E por fim, caracteriza-se como pesquisa bibliográfica, pois se considerou o levantamento de literatura pertinente ao assunto.

\section{DESENVOLVIMENTO}

Um dos procedimentos analíticos para interpretação de dados qualitativos se pautam na Triangulação. Há que se destacar que o termo Triangulação pode ser utilizado em três dimensões diferenciadas, dependendo do contexto em que é empregado, comportando, portanto, divergências conceituais, o que pode levar a equívocos na sua interpretação e compreensão.

Segundo Minayo (2010), em uma primeira dimensão Triangulação, é utilizada para avaliação aplicada a programas, projetos, disciplinas, enfim. No processo avaliativo, sua conceituação tornase abrangente e complexa, abarcando diferentes variáveis, dentre elas, a necessidade de se ter presente avaliadores externos, além dos internos, e que, preferencialmente, sejam de formações distintas, possibilitando "combinação e cruzamento de múltiplos pontos de vista" (MINAYO, 2010, p. 29); a realização de pesquisas quantitativas e qualitativas; a análise do "contexto, da história, das relações, das representações [...], visão de vários informantes e o emprego de uma variedade de técnicas de coleta de dados que acompanha o trabalho de investigação" (MINAYO, 2010, pp. 2829).

No que tange à coleta de dados, a Triangulação permite que o pesquisador possa lançar mão de três técnicas ou mais com vistas a ampliar o universo informacional em torno de seu objeto de pesquisa, utilizando-se, para isso, por exemplo, do grupo focal, entrevista, aplicação de questionário, dentre outros.

Numa terceira dimensão, tem-se o emprego da Triangulação para análise das informações coletadas. Nesse sentido, a técnica prevê dois momentos distintos que se articulam dialeticamente, favorecendo uma percepção de totalidade acerca do objeto de estudo e a unidade entre os aspectos teóricos e empíricos, sendo essa articulação a responsável por imprimir o caráter de cientificidade ao estudo.

O primeiro momento diz respeito à preparação dos dados empíricos coletados, mediante diversos procedimentos a serem adotados. Esses procedimentos são representados por etapas sumárias que visam à organização e o tratamento das narrativas. O segundo momento se refere à análise propriamente dita que implica na necessidade de se refletir sobre: primeiro, a percepção que os sujeitos constroem sobre determinada realidade; segundo, sobre os processos que atravessam as relações estabelecidas no interior dessa estrutura e, para isso, a recorrências aos autores que se debruçam sobre tais processos e sobre a temática trabalhada na pesquisa é 
imprescindível; e terceiro, sobre as estruturas que permeiam a vida em sociedade (MINAYO, 2010).

Dito isso, conclui-se, portanto, que, na Análise por Triangulação de Métodos, está presente um modus operandi pautado na preparação do material coletado e na articulação de três aspectos para proceder à análise de fato, sendo que o primeiro aspecto se refere às informações concretas levantadas com a pesquisa, quais sejam, os dados empíricos, as narrativas dos entrevistados; o segundo aspecto compreende o diálogo com os autores que estudam a temática em questão; e o terceiro aspecto se refere à análise de conjuntura, entendendo conjuntura como o contexto mais amplo e mais abstrato da realidade. A articulação desses três aspectos, para proceder à análise, é elucidada na Figura 1.

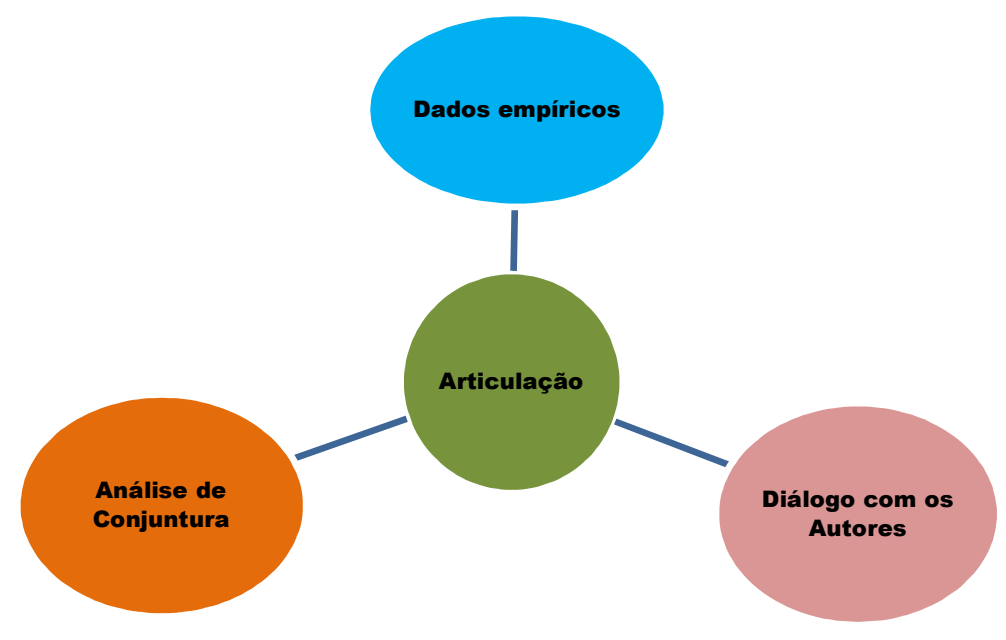

Figura 1 - Análise por Triangulação de Métodos.

Fonte: Elaborado pelas Autoras (2013).

Esta articulação entre dados empíricos, autores que tratam da temática estudada e análise de conjuntura, configura-se como uma possibilidade, dentre várias outras, para os que se propõem minimizar o "distanciamento entre a fundamentação teórica e a prática da pesquisa" (GOMES, 2004, p. 69).

A partir do entendimento dessas três dimensões, salienta-se que, no estudo em que a Triangulação é utilizada para análise qualitativa das informações coletadas, o processo interpretativo deve ser realizado, primeiramente, mediante "uma valorização fenomênica e técnica dos dados primários, em si mesmos e à exaustão". E, posteriormente, num segundo movimento analítico, as informações devem ser "contextualizadas, criticadas, comparadas e trianguladas" (GOMES et al., 2010, p. 185).

A organização do primeiro processo interpretativo, qual seja, valorização fenomênica e técnica das informações coletadas deve ocorrer mediante três etapas: primeiro - preparação e reunião dos dados; segundo - avaliação de sua qualidade; e terceiro - elaboração de categorias de análise.

Na primeira etapa, deve-se transcrever os dados qualitativos levantados. Aqui, é necessário 
dedicar atenção, em caso de narrativa de pessoas, à entonação da voz, silêncios, ênfase em palavras ou expressões, dentre outras observações compreendidas como importantes. À medida que são lidas as transcrições, deve-se realizar as marcações daquilo que se considera relevante na narrativa ou nos dados qualitativos levantados, tendo em conta os eixos estruturadores da pesquisa, seguidos de edição das narrativas ou dos dados coletados e a análise propriamente dita.

Na segunda etapa, deve-se realizar a avaliação dos dados primários coletados, sendo essa fase considerada como uma pré-análise. Os objetivos do estudo devem ser retomados, neste momento, e, após, dar-se início à discussão das categorias anteriormente estabelecidas.

$\mathrm{Na}$ terceira etapa, as narrativas ou dados coletados devem ser trabalhados no sentido de refletir, contextualizar, exemplificar e elucidar as diversas dimensões do estudo que se queira realizar. E, por fim, os dados qualitativos devem ser tratados ainda no sentido de conferir sustentáculos para as conclusões.

No segundo processo interpretativo, deve-se realizar uma "análise contextualizada e triangulada dos dados", objetivando "à reconstrução teórica da realidade" (GOMES et al., 2010, p. 199). A primeira etapa desse segundo momento caracteriza-se pela leitura aprofundada do material selecionado de forma a "impregnar-se pelo conteúdo a fim de alcançar uma visão do conjunto e ao mesmo tempo apreender as particularidades presentes nessa totalidade parcial" (GOMES et al., 2010 , p. 205), ou seja, o assunto tratado na pesquisa, contextualizado com a realidade mais ampla no qual está inserido, realizando mediações reflexivas com o Estado e com a Nação, entre outros aspectos.

A elaboração de alguns questionamentos contribui para essa investigação, tais como: se existem elementos ou aspectos que tenham características comuns nas narrativas ou nos dados coletados, se existem informações distintas em decorrência de uma possível diversidade de contexto do qual as informações emergiram, se os temas, assuntos, opiniões ou dificuldades, no caso de narrativas, mantêm relação entre si, se a informação prestada por um sujeito ou se os dados coletados são diferenciados dos outros e em que dimensão, enfim. Esses questionamentos contribuem para o aprofundamento das informações coletadas que, uma vez respondidas, permitem que se possa partir para a "busca de um quadro mais sintético e mais nítido de temáticas ou eixos orientadores da interpretação" (GOMES et al., 2010, p. 207).

Posteriormente, na segunda etapa, a investigação deve ser ancorada no diálogo com autores que tratam questões pertinentes às categorias de análise emergidas das narrativas ou dos dados coletados. Portanto, em face da necessidade de esclarecimento tanto das categorias quanto dos diversos elementos que surgem no processo de levantamento de dados, dentre outras variáveis analíticas, justifica-se a importância da recorrência aos autores.

Como na investigação científica, a intenção do pesquisador se pauta na ultrapassagem do senso comum, bem como na descentralização das informações coletadas do eixo histórico socialmente condicionado, ou seja, no caso de narrativas, como a "meta é a busca de sentidos das falas e das ações para alcançar a compreensão ou explicação para além dos limites do que é descrito e analisado" (GOMES et al., 2010, p. 202), torna-se imprescindível a interconexão com os autores, aliás não se alcança tal meta sem o auxílio dos autores que estudam as temáticas pertinentes aos assuntos tratados em qualquer que seja a pesquisa. É muito importante ter presente 
que, independente do tipo de pesquisa científica, ela sempre irá englobar "uma instância coletiva de reflexão" (DESLANDES, 2004, p. 36).

Na terceira etapa, denominada "ápice da interpretação", deve-se trabalhar com as questões mais amplas que "articulam modelos subjacentes às ideias" (GOMES et al., 2010, p. 207). A análise de conjuntura deve contemplar o objeto de estudo, contextualizando-o na ambiência macro da sociedade, bem como reflexos dessa realidade macro no espaço particular do objeto de estudo, buscando-se também uma articulação entre as informações coletadas no ambiente imediato com as informações normatizadas, definidas num contexto mais amplo, entendendo que são estas "contextualizações que orientaram o olhar sobre os dados" (GOMES et al., 2010, p. 205). Para tanto, deve-se procurar ir além das informações coletadas, buscando-se ideias por trás das transcrições dos dados, analisando-se, portanto, não somente as informações que se alcançou, mas também o contexto no qual as informações foram geradas.

O terceiro e último processo interpretativo, é caracterizado pela reinterpretação, em outras palavras, uma interpretação das interpretações. Nesse processo, o qual é composto por uma única etapa de trabalho, porém tão importante quanto às demais, deve-se realizar uma construção-síntese mediante diálogo entre os dados empíricos, autores que tratam da temática estudada e análise de conjuntura, num contínuo movimento dialético: uma análise que parte do conhecimento local, mas que permita que se chegue a uma aproximação com a realidade mais ampla (GOMES et al., 2010, p. 207, grifos nossos).

A característica dialética, dessa construção-síntese, reforça a importância da passagem temporal, qual seja, do antes e depois à medida que permite que o pesquisador, continuamente, fortaleça ou substitua os conceitos unificadores e identificadores do objeto ou situação estudada. Compreende-se, portanto, que, a partir da apreensão de informações e de aspectos teóricosconceituais, mais se desenvolve a capacidade de o pesquisador exercitar sua consciência crítica, considerada como um dos objetivos dos que optaram por enveredar-se pelo universo da pesquisa.

Tomando-se por base a definição desse processo interpretativo, considerado ao lado de tantos outros Referenciais Analíticos existentes como uma das indispensáveis ferramentas à construção do conhecimento, compreende-se, portanto, a importância do protagonismo dos pesquisadores que se decidiram por fazer uso desse Referencial, bem como buscar o aprofundamento de sua conceituação. Como consequência desse esforço teórico-prático, pode-se verificar o quanto tais pesquisadores e estudiosos sobre o tema podem oferecer contributos para avanço contínuo da Ciência, da Tecnologia e do Desenvolvimento.

A opção pela Análise por Triangulação de Métodos significa adotar um comportamento reflexivo-conceitual e prático do objeto de estudo da pesquisa sob diferentes perspectivas, o que possibilita complementar, com riqueza de interpretações, a temática pesquisada, ao mesmo tempo em que possibilita que se aumente a consistência das conclusões.

Conforme se verifica na Figura 2, a síntese das etapas processuais interpretativas é apresentada.

Revista Univap - revista.univap.br

São José dos Campos-SP-Brasil, v. 20, n. 35, jul.2014. ISSN 2237-1753 
Primeiro processo interpretativo:

(valorização fenomênica e técnica das informações coletadas)

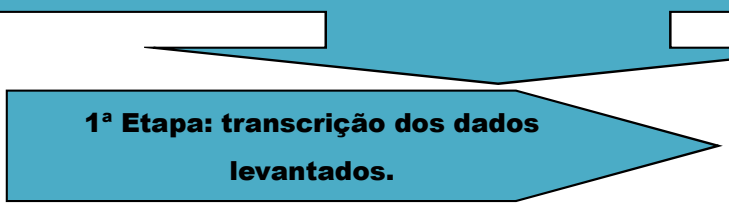

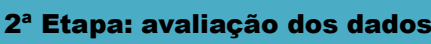
(pré-análise).

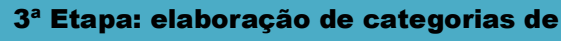
análise.

Segundo processo interpretativo:

(análise contextualizada e trianqulada dos dados)

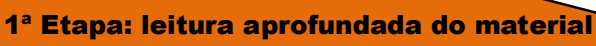

selecionado.

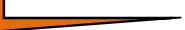

1a Etapar leitura aprofundada do material selecionado.

$2^{a}$ Etapa: investigação ancorada no diálogo com autores.

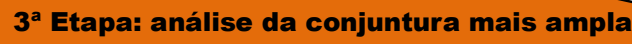
(macro análise).

Terceiro processo interpretativo:

(construção-síntese)

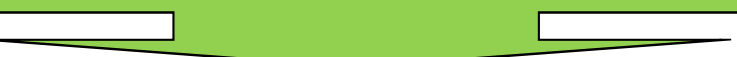

Única Etapa: diálogo entre dados empíricos, autores que tratam da temática e análise de conjuntura.

Figura 2 - Etapas Processuais Interpretativas.

Fonte: Elaborado pelas Autoras (2013). 


\section{CONCLUSÃO}

Como se pode verificar, limitou-se, neste estudo, ao enfoque das questões centrais da Análise por Triangulação de Métodos. Com isso, intenciona-se que novos estudos e reflexões, empenhos e esforços continuem sendo dado por todos aqueles que estejam interessados em dar sua parcela de contribuição para construção de novos conhecimentos a respeito desse Referencial Analítico.

O ato de aprender, de se apropriar de informações e de concepções teóricas para, posteriormente, ter condições de exercitar a própria consciência crítica deve ser considerado como um dos objetivos centrais dos que buscam trilhar pelos caminhos da pesquisa.

Por fim, quanto mais ativo for o protagonismo dos estudiosos que optaram por dar a própria contribuição à retomada contínua dos estudos sobre os Referenciais Analíticos, tão imprescindíveis ao processo de construção do conhecimento, tanto mais próximos tais estudiosos estarão da contribuição que podem oferecer para avanço da Ciência, da Tecnologia e do Desenvolvimento.

\section{REFERÊNCIAS}

DESLANDES, S. F. A construção do projeto de pesquisa. In: MINAYO, M. C. S. (Org.) et al. Pesquisa Social: Teoria, Método, e Criatividade. Petrópolis: Vozes, 2004. pp. 31-50.

GOMES, R. A Análise de Dados em Pesquisa Qualitativa. In: MINAYO, M. C. S. (Org.) et al. Pesquisa Social: Teoria, Método, e Criatividade. Petrópolis: Vozes, 2004. pp. 67-80.

GOMES, R. et al. Organização, processamento, análise e interpretação de dados: o desafio da triangulação. In: MINAYO, M. C. S.; ASSIS, S. G.; SOUZA, E. R. (Org.). Avaliação por triangulação de métodos: Abordagem de Programas Sociais. Rio de Janeiro: Fiocruz, 2010. pp. 185-221.

MINAYO, M. C. S. Introdução. In: MINAYO, M. C. S.; ASSIS, S. G.; SOUZA, E. R. (Org.). Avaliação por triangulação de métodos: Abordagem de Programas Sociais. Rio de Janeiro: Fiocruz, 2010. pp. 19-51.

Ciência, técnica e arte: o desafio da pesquisa social. In: (Org.) Pesquisa Social: Teoria, Método, e Criatividade. Petrópolis: Vozes, 2004. pp. 9-29.

MORESI, E. (Org.). Metodologia da Pesquisa. 2003. 108 f. Trabalho Científico (Especialização em Gestão do Conhecimento e Tecnologia da Informação) Universidade Católica de Brasília, 2003. Disponível em: <http://www.inf.ufes.br/ falbo/files/MetodologiaPesquisa-Moresi2003.pdf>. Acesso em: 19 nov. 2013. 